\title{
The Impact of Folding Shutter on the Daylighting Performance in Tropical Climate
}

\author{
Yasmine Mawaddag Ghufrona, Asri Dinapradipta, and FX Teddy Badai Samodra \\ Departement of Architecture, Institut Teknologi Sepuluh Nopember, Surabaya \\ e-mail: asdina_p@arch.its.ac.id
}

\begin{abstract}
Abstrak - Utilization of abundant sunlight in tropical climates as daylighting can help to save energy consumption in the flats building. Based on daylight conditions in tropics, there is a need for a dynamic shading to be applied in façade which can be transformed to respond to the environmental change. Folding shutter is a dynamic shading device which can be operated by using folding and rotation motion. This paper aims to discuss the impact of folding shutter on the daylight performance in the context of flats buildings in tropical climates. Simulation using Radiance was conducted to test the sub-variables of folding shutter, including the folding configurations and shutter's rotation angles on different conditions in tropics. The results showed that folding configurations results in high increase of daylight intensity and should be applied moderately. Meanwhile the shutter's slats can help to diffuse and reflecting incoming light to the deepest areas of room. A closed configuration with shutter's angle of $0^{\circ}$ and $45^{\circ}$ performed the best to face the inconsistent cloud movement in partly cloudy sky. The integration of folding shutter and $60 \mathrm{~cm}$ overhang produced the most stable performance which can meet the visual comfort standard in the longest period in tropics.
\end{abstract}

Kata Kunci-Daylighting Strategy, Dynamic Shading Device, Folding Motion, Radiance Simulation, Rotation Motion.

\section{PENDAHULUAN}

$\mathrm{D}$ AYLIGHTING importance has been highlighted by previous researches, as it has many positive impacts such as increasing psychological comforts, health, and productivity [1]. Daylighting can also help to decrease the energy consumption of the building [13] and has great benefits to be applied in flats building which mostly used by low-income residents. However, the quality of daylighting is greatly influenced by the geometry of the building, the orientation of the building, the allocation of space, and light openings [20, 12]. Moreover, daylight availability also depends on the sky conditions and sun movement at a certain time or period in each climate.

The tropical climate has an abundant sunlight with solar radiation between 5,500-7,500 wh/m2 [10], and the external illuminance can reach 130,000 lux [14]. The tropical sky is partly cloudy which has rapid changes according to cloud movement and can result in a high daylight intensity [5]. The composition of solar radiation that reaches the earth's surface can vary which is influenced by the sun's altitude angle [13]. To confront the changing environments in tropics, there is a need for dynamic shading systems that can be easily controlled. Dynamic shading device is shading that is adaptive and responsive to environmental conditions because its character that can be moved [17] and can be controlled according to user preferences [16]. Based on that, this paper will use a dynamic shading device as the daylighting strategy within the context of tropical climate.

The performance of a dynamic shading device is strongly influenced by the control system and the type of motion applied. The type of motion which frequently used is translational and rotational, such as those applied to venetian blinds. Whereas a study about more complex dynamic movements such as foldable and deployable shading systems is still limited [11]. Moreover, the integration of different types of movement results in more rich and variable compositions [18]. Folding shutter is the development of a shutter that can be moved by folding motion and rotational motion. The folding motion has such flexibility as it combines the translation and scaling motion [15]. Based on that, this paper aims to investigate the impact of folding shutter on the daylight performance in the context of flats buildings; and to investigate the model configurations which can be applied under different conditions in the tropics.

\section{METHOD}

This paper used an experimental method by computer simulation using Radiance to investigate the daylighting performances of folding shutter variables in tropical climate. The experimental method focuses on the cause and effect relationships using control, independent and dependent variables [6]. Radiance is developed by Greg Ward at Lawrence Berkeley National Laboratories, widely recognised and validated by the lighting professionals. Radiance presents interfaces for modeling and translating space geometry, luminaire data, and material characteristics [19]. However, Radiance has some limitation because it tends to overpredict the direct and global illuminance [4].

\section{A. Base Case}

The base case of this paper is Rusunawa Siwalankerto 2, a flats building with double loaded corridor and open-plan units in Surabaya. The unit is on 5th floor and has a vertical window facing at north orientation. The unit's dimension is $4,5 \times 5,2 \mathrm{~m}$ with $2,7 \mathrm{~m}$ ceiling height. The vertical window's dimension is $120 \times 160 \mathrm{~cm}$ with $70 \mathrm{~cm}$ height from the floor. The folding shutter is placed on outside the window as the second façade. Figure 1 shows the nodes measurement on the floor plan and section of the unit and Figure 2 shows the interior of the base case unit. The grid analysis for the simulation is placed on $80 \mathrm{~cm}$ height from the floor. There is a total of 14 nodes measurement with $100 \mathrm{~cm}$ distance 
The $6^{\text {th }}$ International Seminar on Science and Technology (ISST) 2020

July $25^{\text {th }} 2020$, Institut Teknologi Sepuluh Nopember, Surabaya, Indonesia

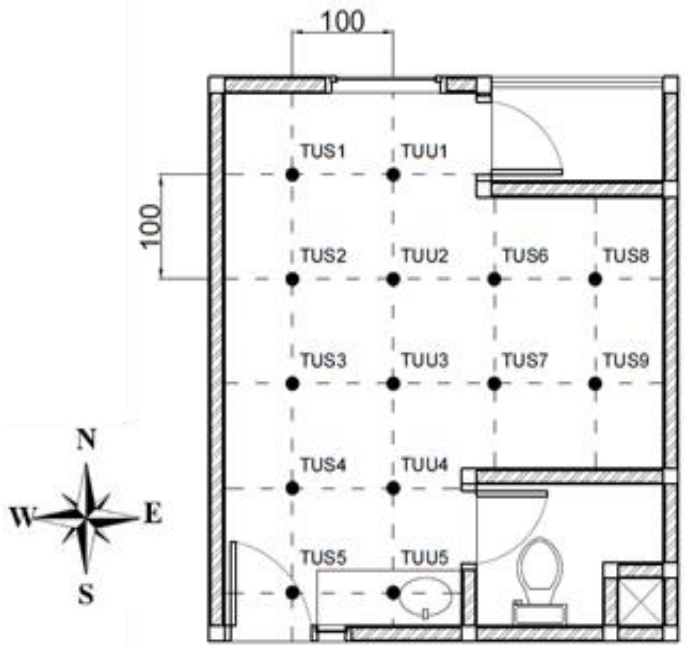

(a)

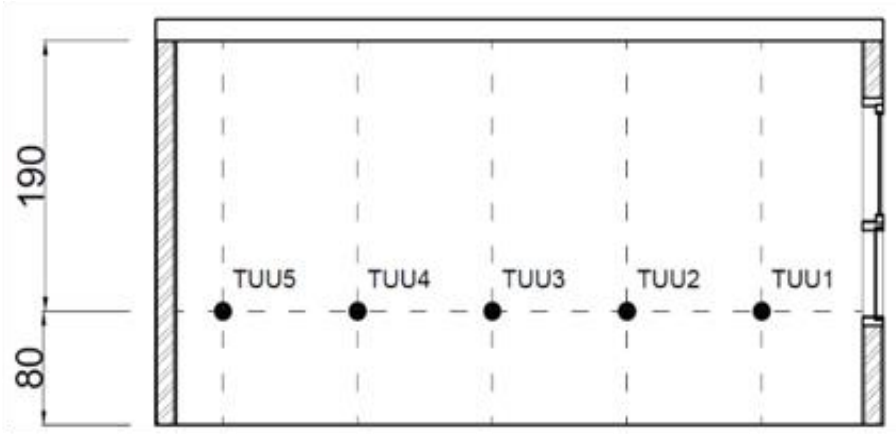

(b)

Figure 1. (a) The nodes measurement on the floor plan; (b) The nodes measurement on the section of the base case.

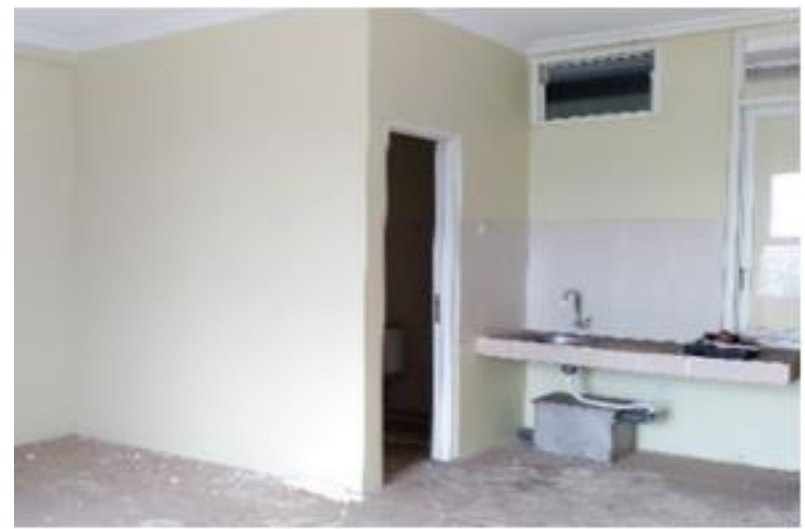

Figure 2. The interior of Rusunawa Siwalankerto 2.

between each node.

\section{B. Variables}

1. Control variables: site location, building orientation (North), tipology and dimension of the unit, color and reflectivity of the interior element, folding shutter's material and shutter slats' geometry.

2. Independent variables: folding shutter models (FS1, FS2, FS3), folding configurations from fully closed configuration (KO1) to fully opened configuration (KO5) in which each configuration is folded by $15^{\circ}$, and shutter's rotation angles of $0^{\circ}, 45^{\circ}, 90^{\circ}, 135^{\circ}$ for the daylight distribution (illuminance) analysis, and $0^{\circ}, 15^{\circ}, 30^{\circ}, 45^{\circ}$, $60^{\circ}, 75^{\circ}, 90^{\circ}, 105^{\circ}, 120^{\circ}, 135^{\circ}, 150^{\circ}, 165^{\circ}$ for the daylight factor analysis. Figure 3 shows the illustration of the folding shutter models. FS1 is a basic folding shutter which is shutters that folded together, FS2 is an integration of shutter and light shelf $60 \mathrm{~cm}$, and FS3 is an integration of shutter and overhang $60 \mathrm{~cm}$. Figure 4 and Figure 5 shows the sub-variables of folding shutter from the application of folding motion and rotational motion. It should be noted that the folding motion simulation will use shutter's rotation angle of $0^{\circ}$ and the rotational simulation will use fully closed configuration (KO1) as the control variables.

3. Dependent variables: illuminance, standard deviation of

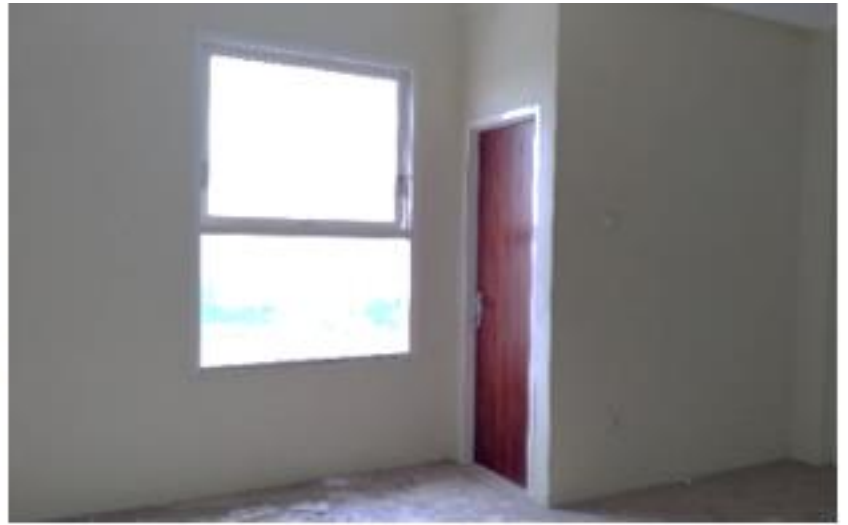

illuminance, and daylight factors.

\section{Simulation Procedure}

This paper using Radiance program to simulate the illuminance and daylight factor for daylight performance analysis. The simulation procedure for each simulation will be explained below.

1. Illuminance simulation on the average condition in tropics (March 21/equinox) under the intermediate sky. This simulation is carried out in the morning (9 AM), noon (12 $\mathrm{PM}$ ), and afternoon (3 PM) during the equinox. The illuminance data will be used to analyze the daylight distribution from TUU1 to TUU5.

2. Daylight factor simulation on the critical condition in tropics (June 21/summer solstice) under the overcast sky. This simulation is carried out at noon (12 PM) automatically from the Radiance program. The daylight factor data will be compared with daylight factor standard for tropical climate (MS 1525:2007) with a range from $2 \%$ to $5 \%$.

\section{RESULT AND DISCUSSION}

\section{A. Daylight Distribution}

In the morning when the sun position is still near the horizon, there is a high contrast of illuminance between 

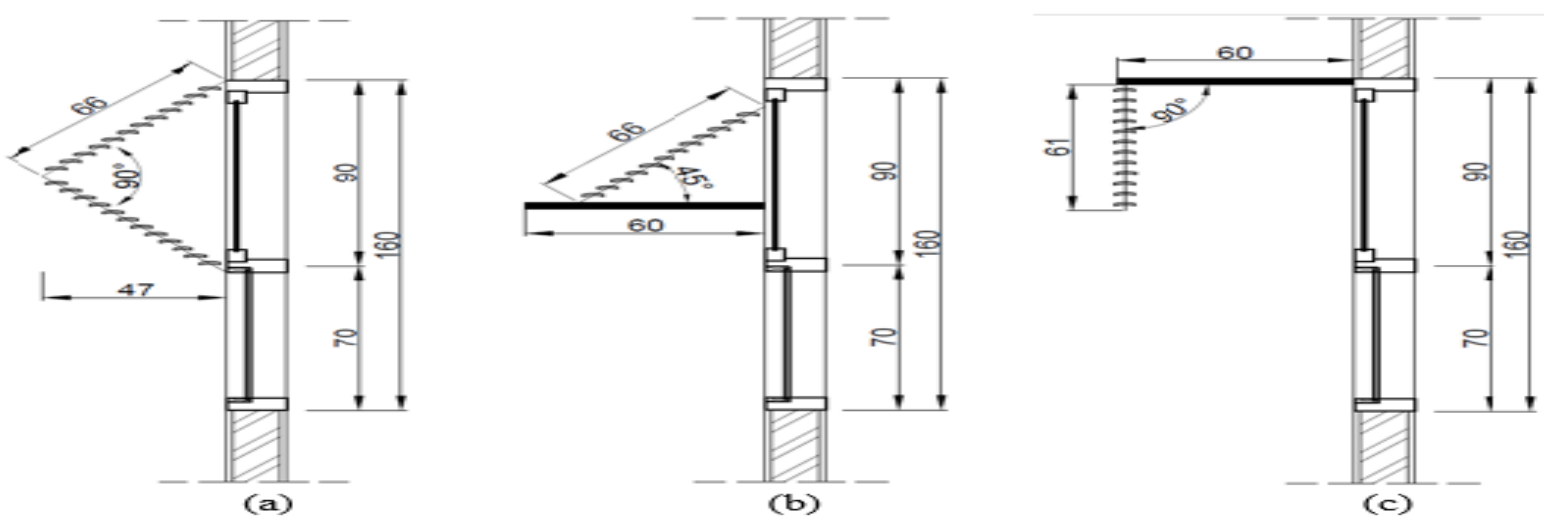

Figure 3. (a) Basic model of folding shutter; (b) Integration folding shutter with light shelf; (c) Integration folding shutter with overhang.

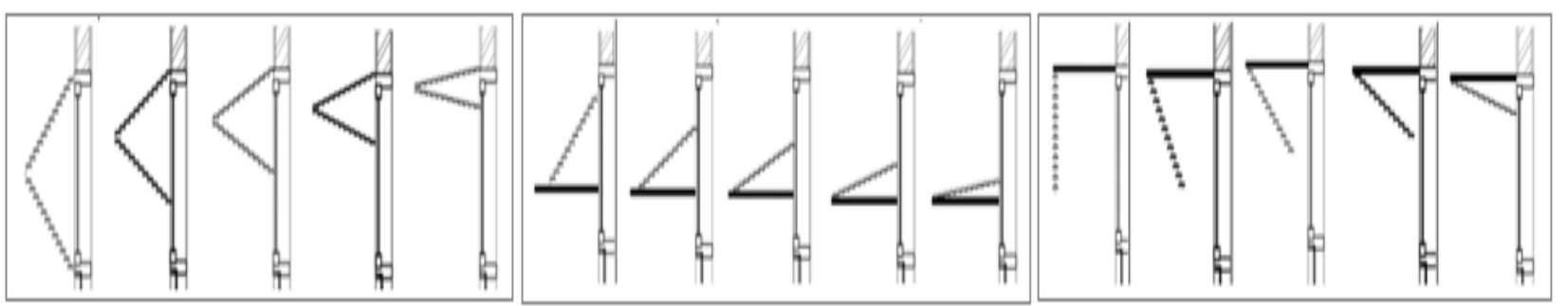

Figure 4. The application of folding motion from KO1 to KO5 on (a) FS1; (b) FS2; (c) FS3.

TUU1 and TUU5 in the base case. Figure 6 shows the daylight distribution in the morning by the application of different shutter's rotation angles in all of the folding shutter models. FS1 can reflects the daylight until TUU5 by $22 \%$ with a rotation angle of $90^{\circ}$. This supported the result of previous research [9], that a sloped shutter can increase the illuminance in the deepest areas of the room. Meanwhile, the integration of shutter and light shelf (FS2) tends to produce a dim daylighting, especially FS2 $-45^{\circ}$ with a $-33 \%$ illuminance decrease inside the room. On the other hand, FS3 can decrease the illuminance in the area near the window (TUU1) from $-21 \%$ to $-34 \%$. All the shutter's rotation angles of FS3 can also increase illuminance until TUU5 quite well by $15 \%$ with the exception of FS3-45 ${ }^{\circ}$.

Daylight distribution analysis for folding motion used the standard deviation of illuminance, in which the standard deviation with lower value indicates more even daylight distribution. Figure 7 shows the standard deviation of different folding configurations in all of the models. Both FS2 and FS3 can distribute the sun inside the room more evenly, especially in fully closed configurations (KO1). FS2 and FS3 are integrated with a solid plane such as light shelf and overhang that can block the direct sunlight more effectively and reduce the high illuminance near the window. Meanwhile, FS1 performed better in a fully opened configuration (KO5). It is because the sloped shutter on FS1 tends to produce high reflections and less effective in blocking direct sunlight. Previous research [8] also stated that folding shading with a solid plane functioned better in providing full shade and reducing the heat effects by solar radiation.

At noon, the source of daylighting is a diffused light which has lower daylight intensity than direct sunlight. The base case has a high decrease of illuminance from TUU1 to TUU5.
Figure 8 shows the daylight distribution at noon by the application of different shutter's rotation angles in all of the folding shutter models. From all the shutter's rotation angles, $\mathrm{FS} 1-0^{\circ}, \mathrm{FS} 2-90^{\circ}$, and $\mathrm{FS} 3-0^{\circ}$ results in the best daylight distribution in the room. FS2 $-90^{\circ}$ can increase the illuminance up to TUU5 by $40 \%$ because most of the daylight is reflected by the light shelf. Rotating the shutter's slats by $0^{\circ}$ to FS 1 and FS3 can increase the illuminance in the deepest areas of the room. Previous research [3] also indicated that a rotation angle of $0^{\circ}$ can produce the most adequate indoor illuminance. Between all the folding configurations there is no big difference in standard deviation values, but the fully closed configuration (KO1) performed slightly better than the rest. Meanwhile, FS1 results in more even distribution if the model fully folded (KO5) as it can block the direct sunlight better.

Figure 9 shows the daylight distribution in afternoon by the application of different shutter's rotation angles in all of folding shutter models. Even though the average illuminance of the base case in the afternoon is quite high (2235 lux), but the daylight distribution can reach the deepest areas of the room better than in the morning. The application of FS1 $-0^{\circ}$, FS2 $-45^{\circ}$ and $\mathrm{FS} 3-45^{\circ}$ provides the best shade that result in even daylight distribution. This reinforces the results of previous research $[3,14]$ that a rotation angle of $45^{\circ}$ can reduce the daylight contrast and the maximum illuminance for residential buildings. Whereas the rotation angle of $135^{\circ}$ produces the worst daylight distribution with the highest decrease of illuminance inside the room. This is because the rotation angle of $135^{\circ}$ is almost parallel to the sun's altitude angle in tropical climate during the equinox. All of the models can distribute the daylight better with fully closed configurations (KO1) as it can reduce the high illuminance in 

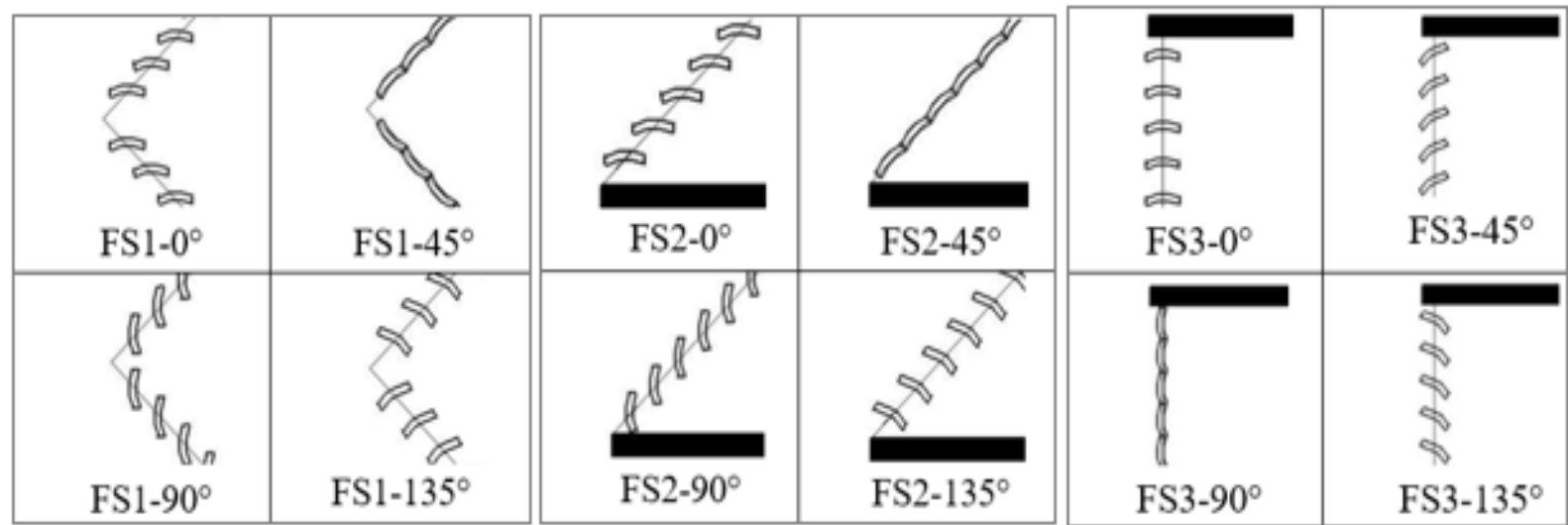

Figure 5. The application of rotation angle of $0^{\circ}, 45^{\circ}, 90^{\circ}, 135^{\circ}$ on (a) FS1; (b) FS2; (c) FS3.

DAYLIGHT DISTRIBUTION OF FS1

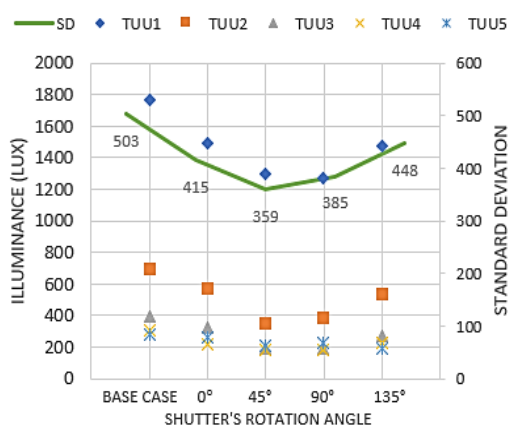

DAYLIGHT DISTRIBUTION OF FS2

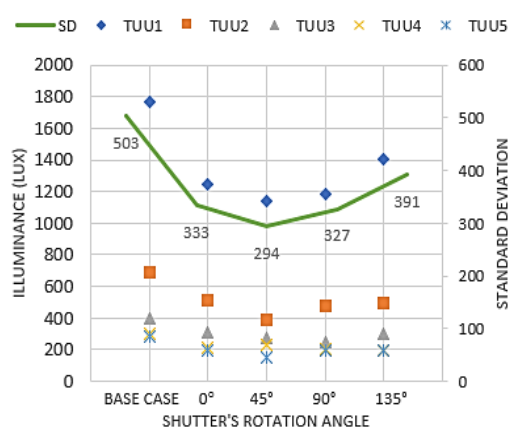

DAYLIGHT DISTRIBUTION OF FS3

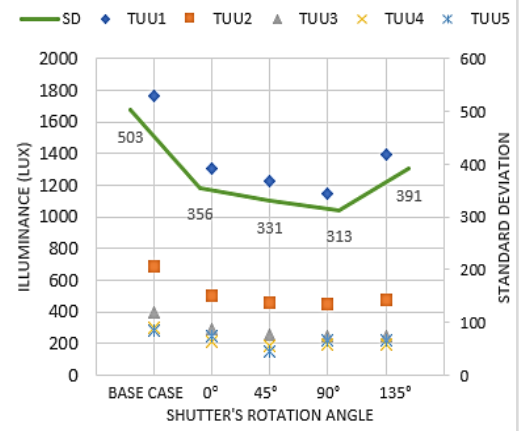

Figure 6. Daylight distribution in morning (9 AM) by the application of rotational motion in each models, (a) FS1; (b) FS2; (c) FS3.
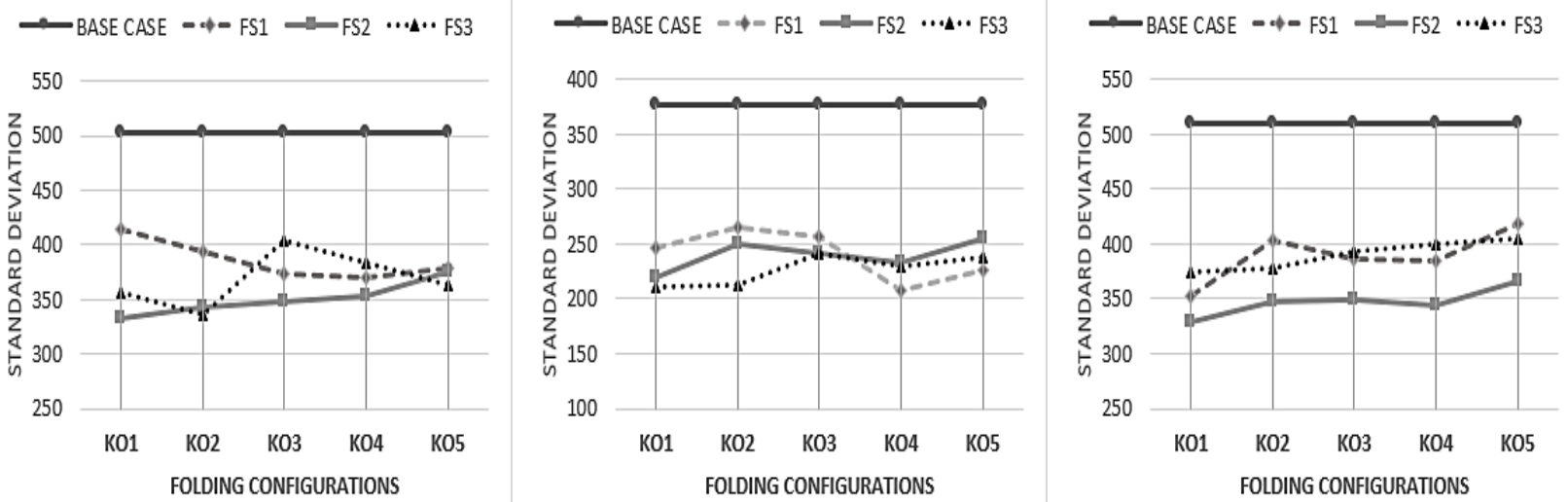

Figure 7. Standard deviation of illuminance by the application of folding motion, (a) in morning; (b) at noon; (c) in afternoon.

TUU1 up to 200 lux by providing full shade from the direct sunlight.

\section{B. Comparison with Daylight Factors Standard}

From the simulation results, it was found that the base case produces a high daylight factors with maximum daylight factors $13.11 \%$ and average daylight factors $4.97 \%$. The average daylight factors in the base case is almost close to $5 \%$, which is too bright for the human visual comfort [2]. Figure 10 shows the average daylight factors of all the folding shutter models by rotational motion from $0^{\circ}$ to $180^{\circ}$. The application of folding shutter can reduce the average daylight factors in the base case closer to the standard (2-5\%). FS1 has a high fluctuations of daylight factors, especially FS1 $-45^{\circ}$ has the highest value from all the shutter's angles. Whereas FS2 has quite constant daylight factors value, except for FS2-90 which has the highest value $(4,43 \%)$. It is because the daylight reflection of FS2-90 ${ }^{\circ}$ is quite high that it can increase the daylight intensity in the rear space of the unit. Meanwhile, the average daylight factors of FS3 tend to keep increasing if the shutter's slats are rotated from $90^{\circ}$ to $180^{\circ}$.

From the simulation results, all of the folding shutter models can produce daylighting above the minimum daylight factors standard of $2 \%$. This indicated that there are no dark problems on the daylighting performance. The percentage of nodes that meet the daylight factors standard (2-5\%) is shown in Figure 11. In the base case, there are only $71 \%$ of nodes measurement which can meet the daylight factors standard. Meanwhile, the application of folding shutter can manage to increase the percentage by $15 \%$. FS3 can meet daylight factor 
The $6^{\text {th }}$ International Seminar on Science and Technology (ISST) 2020

July $25^{\text {th }} 2020$, Institut Teknologi Sepuluh Nopember, Surabaya, Indonesia

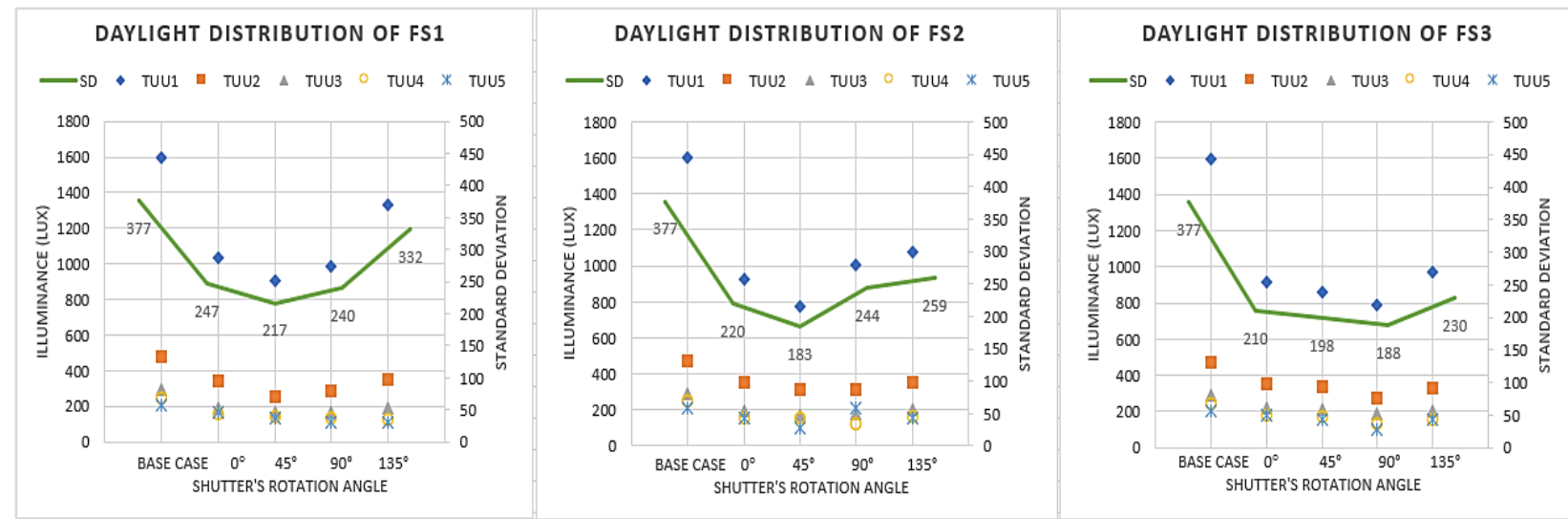

Figure 8. Daylight distribution at noon (12 PM) by the application of rotational motion in each models, (a) FS1; (b) FS2; (c) FS3.

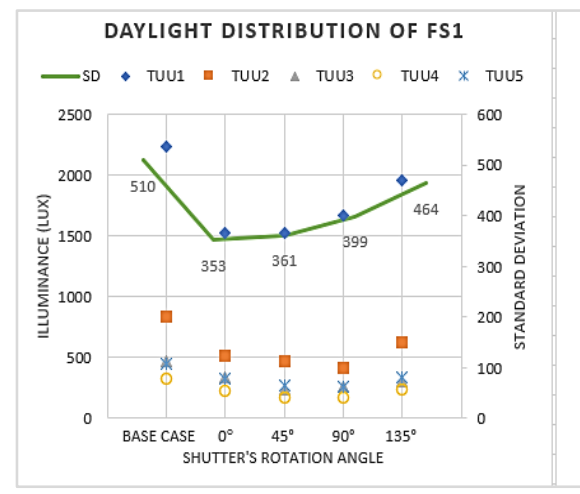

(a)

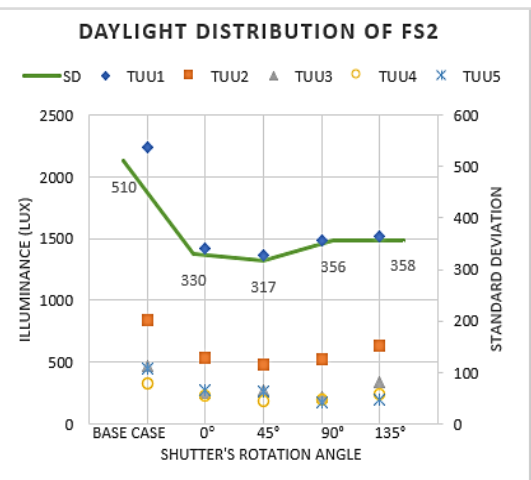

(b)

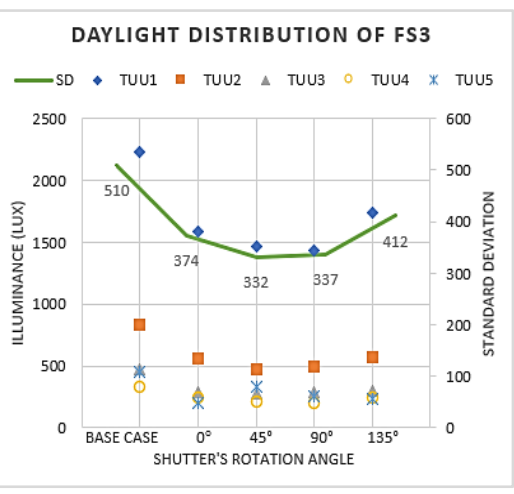

(c)

Figure 9. Daylight distribution in afternoon (3 PM) by the application of rotational motion in each models, (a) FS1; (b) FS2; (c) FS3.

standards most angle of $60^{\circ}$ to $90^{\circ}$ on all folding shutter models results in $86 \%$ nodes that meet the daylight factor standard. This result is compatible with previous research [7] that the shutter's rotation angle of $60^{\circ}$ facing the north orientation tends to produce a low illuminance but is more effective in reducing the side effects of sun radiation.

The folding motion from the fully closed (KO1) to fully opened configurations (KO5) on FS2 and FS3 results in an increase of average daylight factors by $3 \%$. FS1 produces the highest daylight factors consistently in all the folding configurations. This can be caused because FS1 has more shutter's slats than the other models, which results in more reflection of daylight. The simulation results of all folding configurations also exceeds the minimum daylight factors (> $2 \%)$. Figure 11 also shows that the configuration with the lowest daylight factors value can meet the daylight factors standard better. From the other models, FS3 can meet the daylight factors standard with the highest percentage $(86 \%)$ constantly from KO1 to KO5. Meanwhile, FS1 can meet the daylight factors standard with a highest percentage on fully closed (KO1) and fully opened configurations (KO5). That is because the fully folded FS1 has the same form with overhang, which can provide a good shading [2]. On the other hand, the daylight performance of FS2 tends to exceeds the the daylight factors standard (>5\%) from $\mathrm{KO} 3$ to $\mathrm{KO}$.

\section{Discussion}

The experimental results showed that the sloped shutter (FS1 and FS2) can reflect daylight better than the horizontal shutter because each shutter slats receives direct contact with sunlight. However, the sloped shutter is less efficient to reduce the high intensity of daylight, especially if it is applied to the flats building units on the highest floor. However, daylighting control can be done by rotating the angle of the shutter on the folding shutter. The rotation angle of $0^{\circ}$ had been proven to reflect daylight the best on both the sloped shutter and horizontal shutter. In the most critical condition in tropical climates (summer solstice), the rotation angle of a $45^{\circ}$ and $90^{\circ}$ can provide the best shade to block the direct sunlight. It showed compatibility with the result of previous research [14]. Meanwhile, the rotation angle of $135^{\circ}$ can't project the incident light properly because it is almost parallel to the sun's altitude angle in a tropical climate.

From all the folding models that were tested, FS1 can reflect daylight to the deepest areas of space the best. However, the sloped shutter results in too bright daylight performance that exceeds the daylight factor standards. Even though FS1 can distribute the daylight evenly, but its application potentially causes visual discomfort because of the high daylight intensity. On the other hand, the integration of folding shutter with the light shelf (FS2) results in an uneven distribution of light. This is mostly caused by the shutter's position, which becomes an obstruction for the daylight access on the light shelf. Except for FS2- $0^{\circ}$ and FS2$90^{\circ}$, the application of rotation motion results in a high decrease of illuminance. Based on that, FS2 can't work well for the flats building because it potentially caused a high contrast of illuminance. 
The $6^{\text {th }}$ International Seminar on Science and Technology (ISST) 2020

July $25^{\text {th }} 2020$, Institut Teknologi Sepuluh Nopember, Surabaya, Indonesia

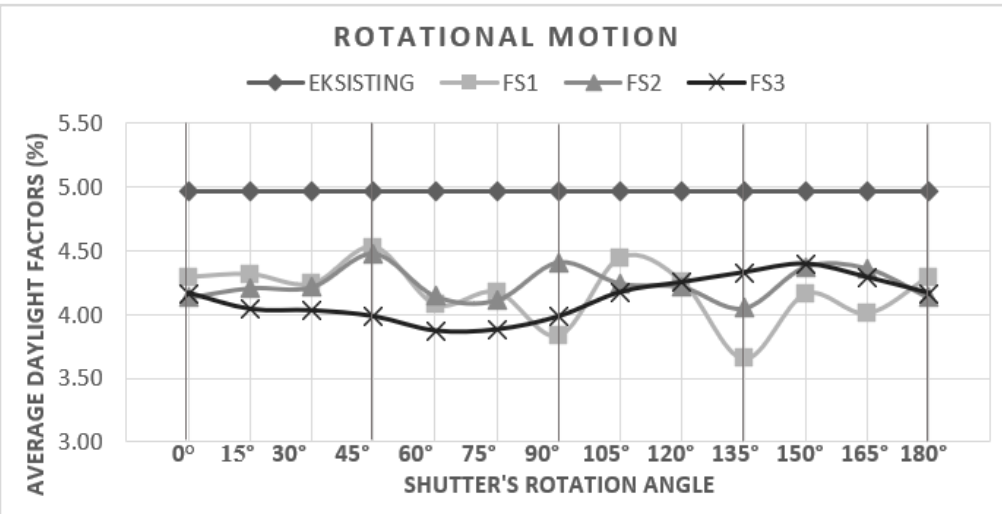

(a)

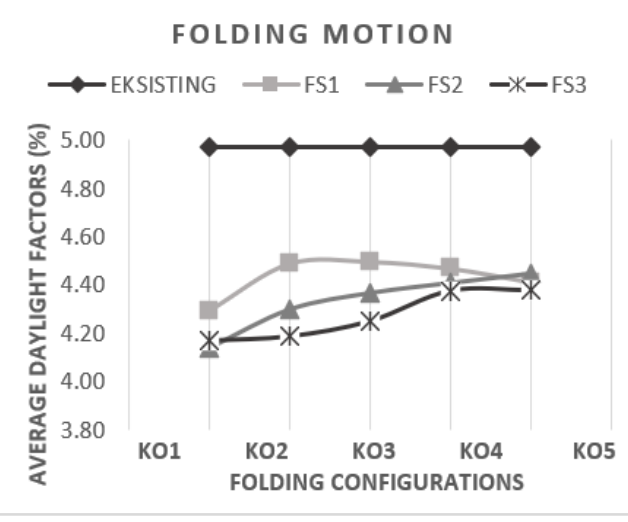

(b)

Figure 10. The average daylight factors by the application of (a) rotational motion; and (b) folding motion.

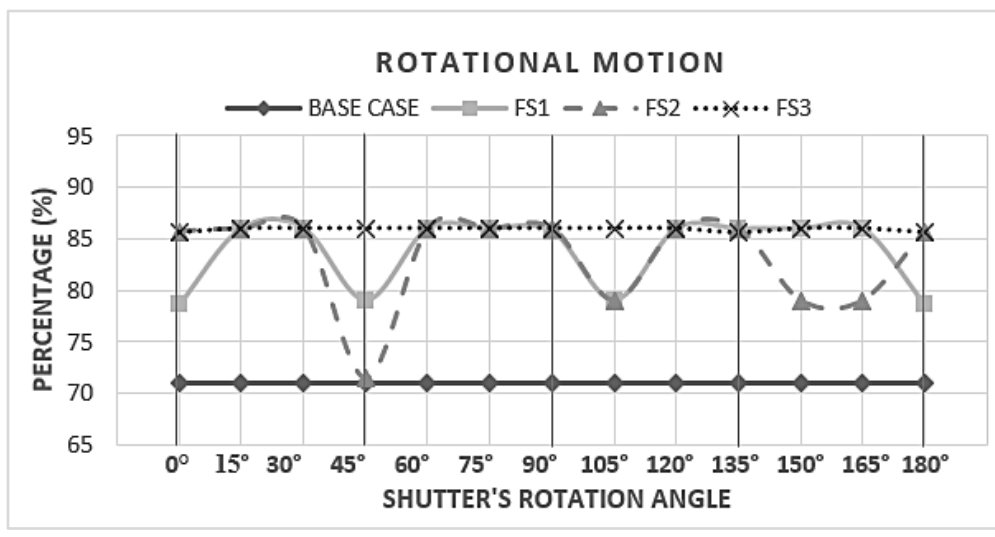

(a)

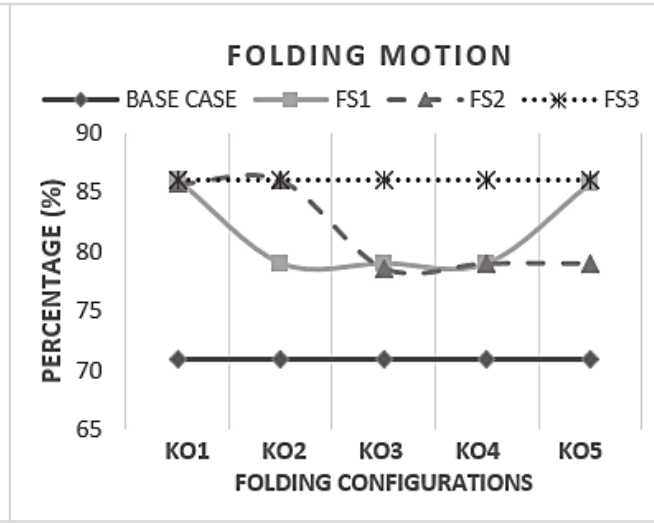

(b)

Figure 11. The percentage of nodes that meet the daylight factor standard by the application of (a) rotational motion; and (b) folding motion.

The integration of folding shutter and overhang (FS3) has the most stable daylight performance and the highest percentage of nodes that can meet the daylight factor standards. The performance is greatly influenced by the overhang, which can block the direct sunlight effectively to reduce the high daylight intensity near the window. still include adequate natural lighting. The overhang was proven able to withstand exposure to light from high altitude angles in the tropics. The shutter which is positioned under the overhang also can helps to diffuse the incident light before reflecting it inside the room.

From the simulation results, the application of folding motion results in the high increase of illuminance, therefore the folding motion should not be applied during the most critical conditions when the outside illuminance is already high. The daylight is better to be distributed through the gaps of the shutter because it can diffuse the daylight intensity better. To confront the changing conditions in tropical climates, the application of closed configurations (KO1) and shutter's rotation angle of $0^{\circ}$ and $45^{\circ}$ can reflect and diffuse daylight effectively. As for the most critical conditions in tropics under the overcast sky, the application of closed configuration (KO1) and shutter's rotation angle from $60^{\circ}$ to $75^{\circ}$ can help to block the direct sunlight while entering allowing enough light to enter. Meanwhile, during the critical condition when there is a need for many daylights, the application of semi to fully opened configurations (KO3KO5) is recommended to increase the average illuminance while providing access to the outside view.

\section{CONLUSION}

Utilization of daylighting is one of the energy conservation efforts for flats buildings that are inhabited by the middle to lower classes of residents. In dealing with the dynamics of conditions in tropical climates, it is necessary to control the daylight by using a dynamic shading device. Based on the simulation result, the folding motion can be used to control the quantity of incoming light. However, the folding motion can result in a high increase of daylight intensity, therefore it is unsuitable to apply in critical conditions in tropics. On the other hand, rotating the shutter from $0^{\circ}$ to $90^{\circ}$ can diffuse daylight effectively and control the direction of reflected light. However, rotating the shutter more than $90^{\circ}$ needs to be avoided as it results in uneven daylight distribution.

The integration of the folding shutter with an overhang of $60 \mathrm{~cm}$ produced the best daylight performance that can meet the visual comfort standard, especially in the most critical conditions in tropics. The integration of the two shadings results in synergic daylight performance because it can block the direct sunlight while reflecting the diffused lights into the room. Its application can also help to manage a stable daylight 
The $6^{\text {th }}$ International Seminar on Science and Technology (ISST) 2020

July $25^{\text {th }} 2020$, Institut Teknologi Sepuluh Nopember, Surabaya, Indonesia

performance to anticipate the changing environments in tropics. By employing a dynamic shading device to control the daylight in the upper window, the lower part of the window can be utilized for ventilation access and displaying the outside views.

It should be noted that the experiment in this paper only uses computer simulation and has not gone through physical testing in real conditions in tropical climates. It does not rule out the possibility that new adjustments can occur in the process of preparing the physical model, which can result in a slightly different daylight performance. Nevertheless, the simulation results showed the daylight performance of the application of the folding and rotational motion, especially in dealing with the different conditions in the tropical climate. Providing a daylighting which can meet the visual comfort standards consistently can help to reduce the energy consumption of artificial lighting in flats building. Besides, by controlling the access of direct sunlight, other side effects from the sun like solar heat gains can also be avoided. Thus, the benefits of the environment can be utilized more in buildings to support the users' comfort. Continuation of this study should include validation of the results through testing of a built prototype. Further studies are also needed in the optimization of folding motion and modification of shutter's slats.

\section{DAFTAR PUSTAKA}

[1] Al Dakheel, J., "Building Applications, Opportunities and Challenges of Active Shading Systems: A State-Of-The-Art Review". MDPI : Civil Engineering \& Architecture, vol. 55, no. 1, 2017, pp. 84-97.

[2] Baker, N., "Daylight Design of Buildings". London: James \& James, 2002.

[3] Carletti, C., Sciurpi, F., Pierangioli, L., Asdrubali, F., Pisello, A.L., Bianchi, F., Sambuco, S., dan Guattari, C., "Thermal and lighting effects of an external venetian blind: Experimental analysis in a full scale test room". Building and Environment, vol. 106, pp. 45-56, 2016.

[4] Dubois, M.C., "Shading devices and daylight quality: an evaluation based on simple performance indicators". Light. Res. Technol. vol. 35, pp. $61-76,2003$

[5] Givoni, B., "Climate Considerations in Building and Urban Design". Architecture and Climate. New Jersey: John Wiley \& Sons, 1998.

[6] Groat, Linda N. dan Wang, David., "Architectural Research Methods". New Jersey: John Wiley \& Sons, 2013.

[7] Hernández, F.F., López, J.M.C., Suárez, J.M.P., Muriano, M.C.G., Rueda, S.C., "Effects of louvers shading devices on visual comfort and energy demand of an office building. A case of study." Energy Procedia, vol. 140, pp. 207-216, 2017.

[8] Kensek, K. dan Hansanuwat, R., "Environment Control Systems for Sustainable Design: A Methodology for Testing, Simulating and Comparing Kinetic Facade Systems". Journal of Creative Sustainable Architecture \& Built Environment. vol. 1, pp. 27-46, 2011.

[9] Kim, Jeong \& Kim, Gon., "Advanced External Shading Device to Maximize Visual and View Performance". Indoor and Built Environment. vol. 19, pp. 65-72, 2010.

[10] Koenigsberger, O.H et al, "Manual of Tropical Housing and Building, Part 1 Climatic Design", Hyderabad: Orient Blackswan Private Limited, 2013.

[11] Konstantoglou, Maria dan Tsangrassoulis, Aris, "Dynamic operation of daylighting and shading systems: A literature review", Renewable and Sustainable Energy Reviews, Elsevier, vol. 60, pp. 268-283, 2016.

[12] Latifah, Nur Laela,. "Fisika Bangunan 1". Bandung: Griya Kreasi, 2015.

[13] Lechner, N., "Heating, Cooling, Lighting: Design Methods for Architects", 4th edition. New Jersey: John Wiley \& Sons, 2015.

[14] Lim Y.W., Zin M, Hamdan M, Remaz D., "Building façade design for daylighting quality in typical government office building". Build and Environment, vol. 27, pp. 194-204, 2012.

[15] Moloney, J., "A Morphology of Pattern for Kinetic Facades". Melbourne: University of Melbourne, Melbourne School of design, 2009.

[16] Nicol, J.F., Humphreys, M.A., "Adaptive thermal comfort and sustainable thermal standards for buildings". Energy Building. vol. 24 no. 2, pp. 563-572, 2002.

[17] O'Brien, W., Kapsis, K., Athienitis, A.K., "Manually-operated window shade patterns in office buildings: a critical review". Building Environment. vol. 60, pp. 319-338, 2013.

[18] O. Schaeffer, M.M. (2010). "Move: Architecture in Motion-Dynamic Components and Elements". Vogt: Walter de Gruyter, 2010.

[19] RADSITE, “About Radiance," Available: https://www.radianceonline.org/about/ [Accessed: 29-July-2020]

[20] Wong," "A review of daylighting design and implementation in buildings". Renewable and Sustainable Energy Reviews, vol. 74, pp 959-968, 2017.

[21] W.-K. Chen, Linear Networks and Systems.Belmont,CA: Wadsworth, pp. 123-135, 1993. 